\title{
Dental microwear of a Late Triassic dinosauriform, Silesaurus opolensis
}

Tai Kubo and Mugino O. Kubo

Acta Palaeontologica Polonica 59 (2), 2014: 305-312 doi: http://dx.doi.org/10.4202/app.2013.0027

Silesaurus opolensis belongs to Silesauridae, the closest sister group to dinosaurs. The present study analyzed the dental microwear patterns of Silesaurus opolensis. Low pit-to-scratch ratios imply they did not feed on hard objects. Unimodal distributions of both wear-facet and non-facet scratch orientations indicate simple orthal jaw movement. Scratch orientation and density differ between microscopic regions in Silesaurus, and unlike hadrosaurid dinosaurs, the microwear patterns of small areas are not identical to those of whole teeth.

Key words: Dinosauriformes, Silesaurus opolensis, dental microwear, jaw movement, herbivory, Triassic, Poland.

Tai Kubo [t-kubo@ dinosaur.pref.fukui.jp], Fukui Prefectural Dinosaur Museum, 51-11 Terao, Muroko, Katsuyama, Fukui 911-8601, Japan; Mugino O. Kubo [mugino@um.u-tokyo.ac.jp], The University Museum, The University of Tokyo, 7-3-1 Hongo, Bunkyo-ku, Tokyo 113-0033, Japan.

This is an open-access article distributed under the terms of the Creative Commons Attribution License (for details please see creativecommons.org), which permits unrestricted use, distribution, and reproduction in any medium, provided the original author and source are credited. 